\title{
لجان تقصي الحقائق في المجال المالي
}

\author{
دكتور \\ سعود طامي العجمي \\ الكويتـوزارة الداخلية
}





\section{المقدمة}

تضع الدساتير تحت تصرف السلطة التشريعية- وهي البرلمانات التي تُمثل الثعب مصدر السلطات (1) - وسائل لتمارس حقها في الرقابة على أعمال السلطة التتفيذية، وللأخيرة في مقابل ذلك وسائلها التي تستطيع

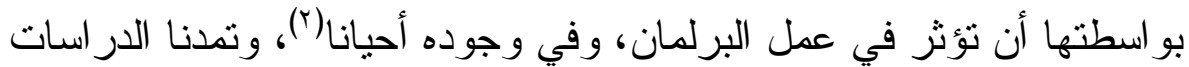

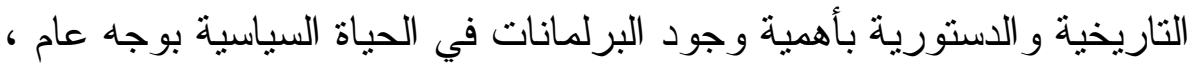
ودور ها في المحافظة على أمو ال الثعب على وجه الخصوص ،كتعبير عن السلطة التشريعية التي تُمثل الثعب مصدر السلطات (ץ) ، و المنوط بها حماية مصالحه (๕) ، نظر الما بؤديه المجال المالي من دور بالغ الأهمية في حياة الثعوب.

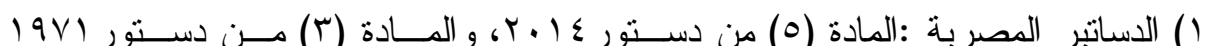

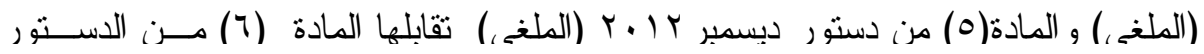

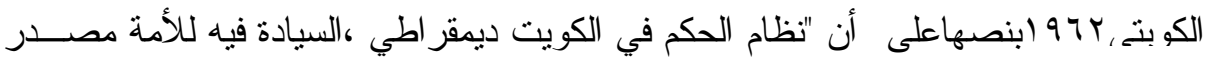
السلطات...." (1) (Y) راجع في شأن التأثير المنبادل بين السلطنين النشريعية والتنفيذية في النظام البرلماني: FÄVOREU (LOUIS) etFRÉDÉRIQUE (RUEDA), Droit constitutionnel, 7e éd., Dalloz, 2004, p54.

RUEDA, FREDERIQUE, le contrôle de l'activité du pouvoir exécutif par le juge constitutionnel: les exemples français, allemand et espagnol, paris (Librairie générale de droit et de jurisprudence :LGDJ), 2010. P33.

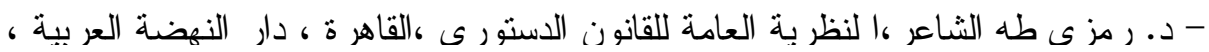

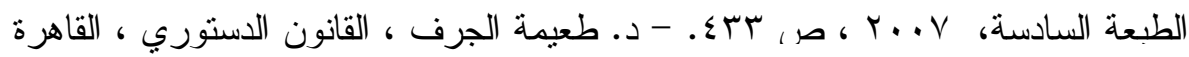

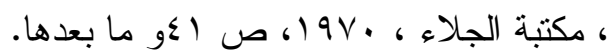

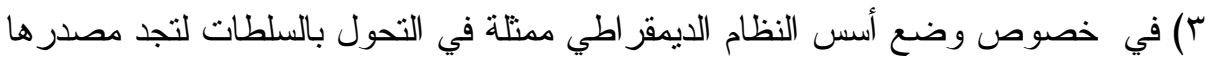

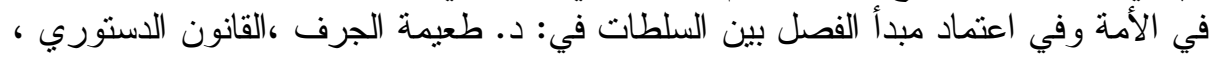

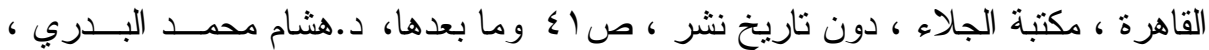

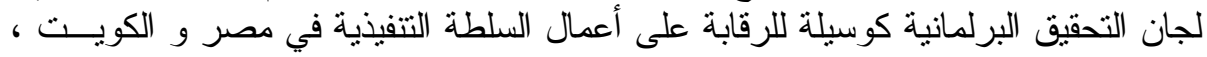

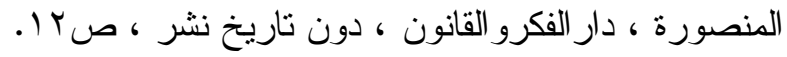

(4) ELISE CARPENTIER, La résolution juridictionnelle des conflits entre organes constitutionnels, LGDJ , 2009, p149 . 
من أجل ذلك كان جدير اً أن تتبنى الدساتير فكرة المحافظة على كل ما

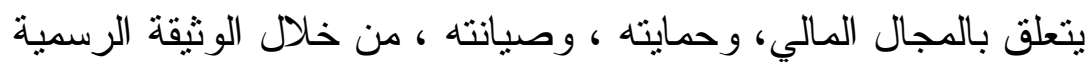

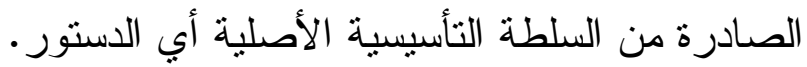
ومن المسلم به أن كل البرلمانات و النظم السياسية قاطبة تر اقب البعة أعمال ونشاط السلطة التتفيذية، إلا أنها تختلف في نطاق تلك الرقابة تبعا للعلاقة بـين

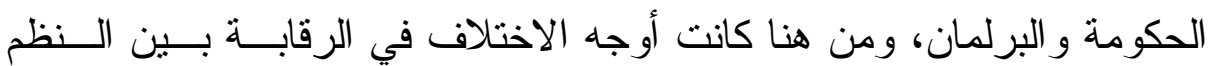
البرلمانية و النظم الرئاسية و النظم المجلسية ( حكومة الجمعية ) .

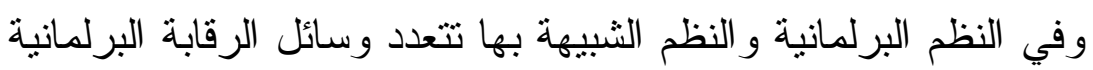

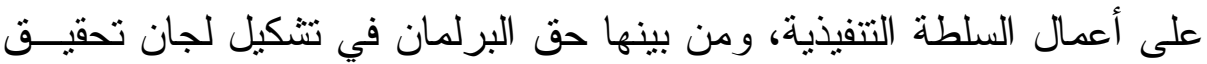

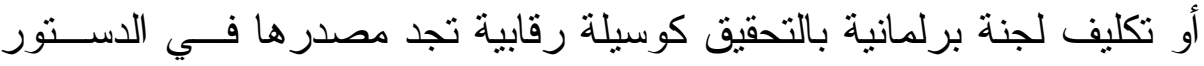

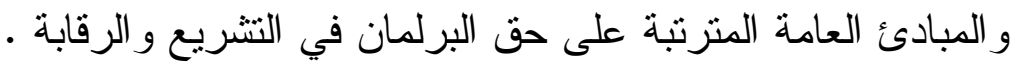

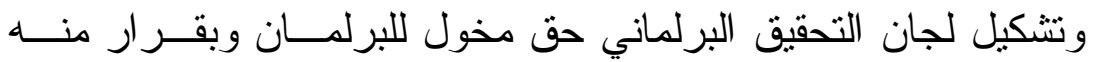

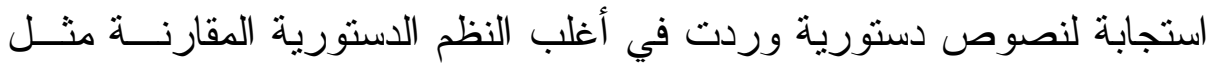

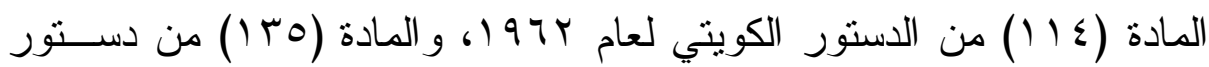

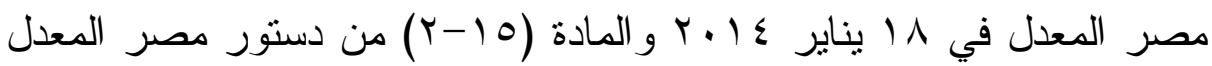

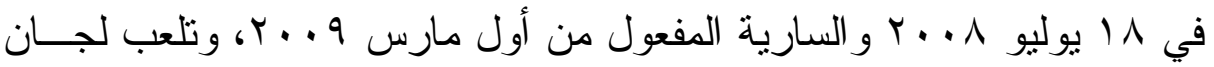

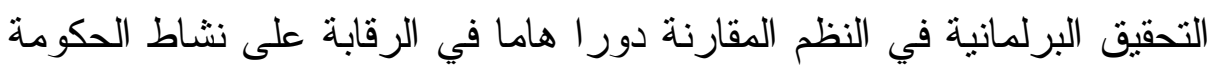

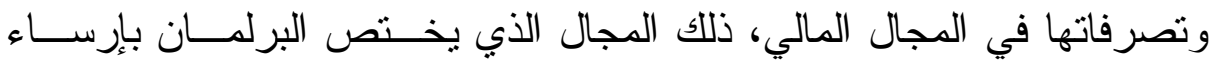

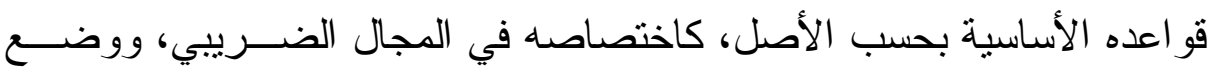

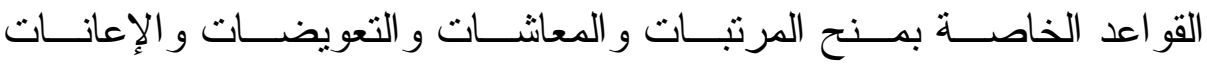

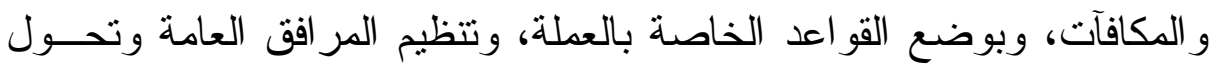

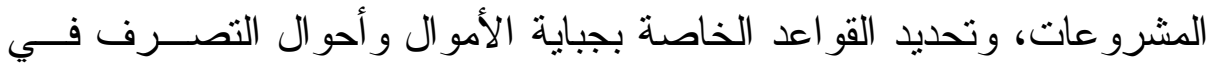

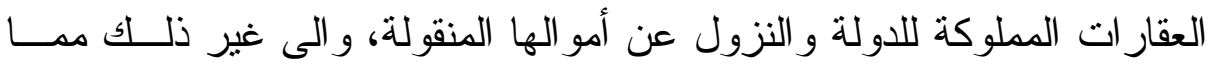
يدخل في اختصاص البرلمان بوضع القو اعد الأساسية في المجال المالي.

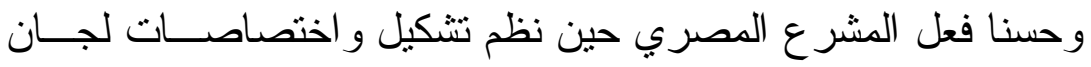

التقصي الحقائق بمجلس النواب في ظل اللائحة الداخلية للمجلس التي صدرئ صدرت

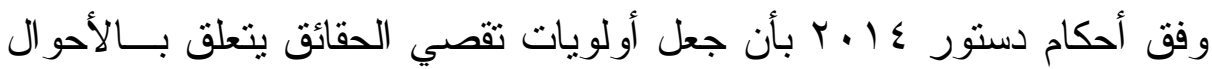

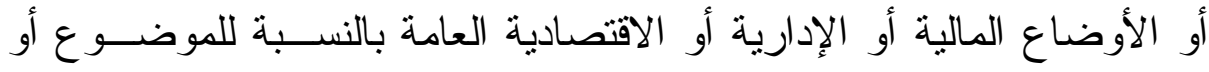

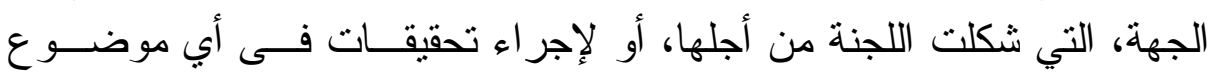


يتعلق بعمل من الأعمال السابقة، وكذلك للتحقق مــن مــدى التـز ام أي مــن

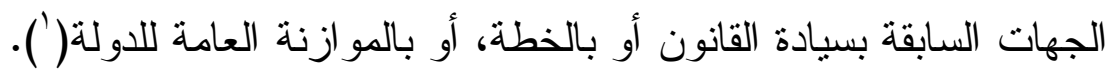
أهمبة الدر اسة:

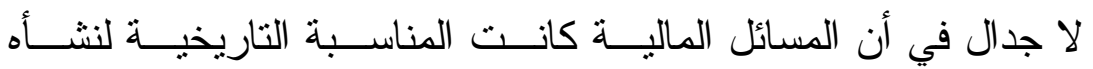

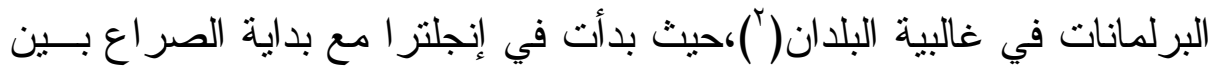

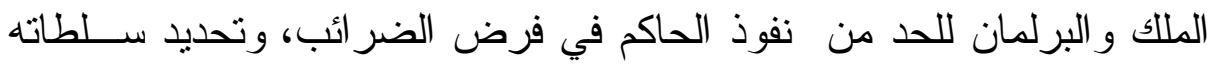

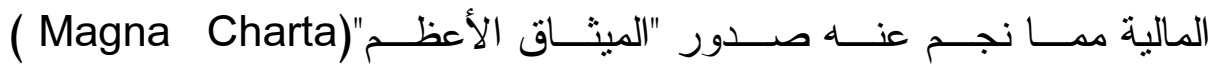

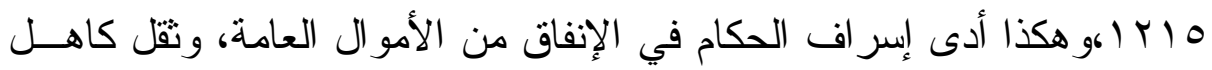

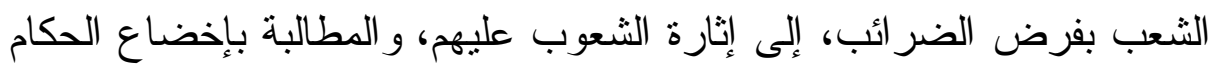

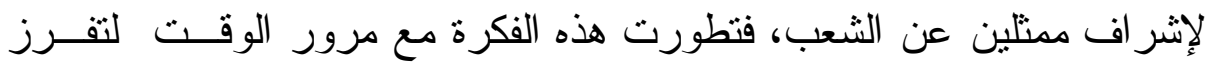

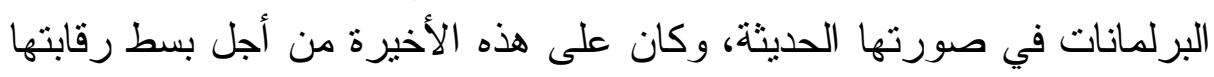

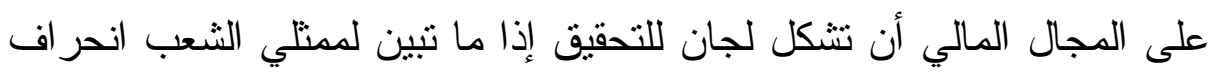
السلطة التتفيذية عن الطريق الدستوري المرسوم لها في المحافظة على المــال

خطة البحث:

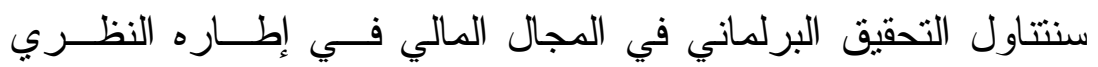
وو اقعه العملي في مبحثين على النحو التالي: المبحث الأول: التحقيق البرلماني في المجئ المال المالي في إطاره النظري المبحث الثاني: التحقيق البرلماني في المجال المالي في المي في و اقعه العملي فلي الماره الني

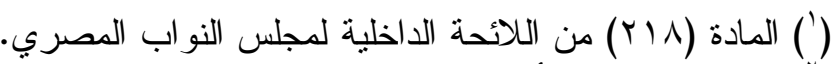

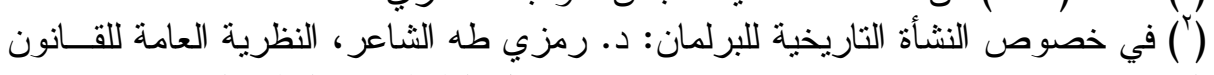

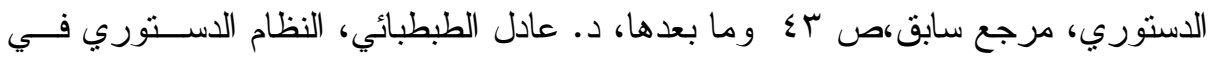

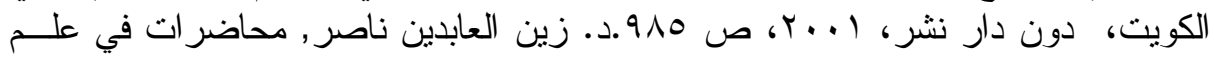

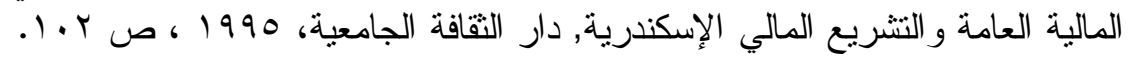




\section{المبحث الأول}

التحقيق البرلماني في المجال المالي في إطاره النظري

التحقيق البرلماني - على هذا النحو - يعد من الوسائل الرقابية متعددة الرئي

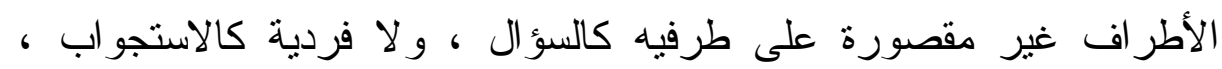

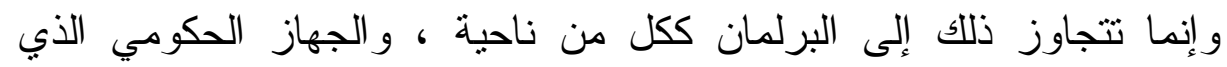

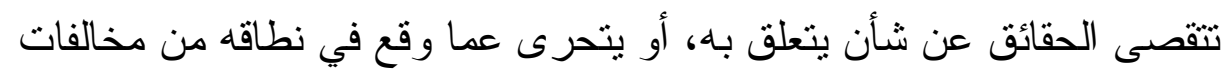

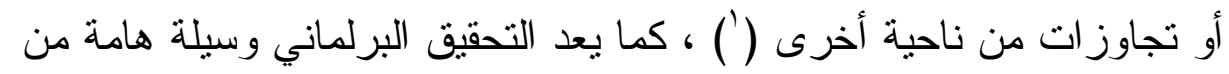

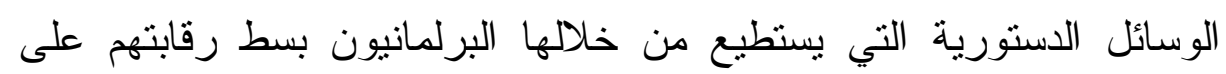

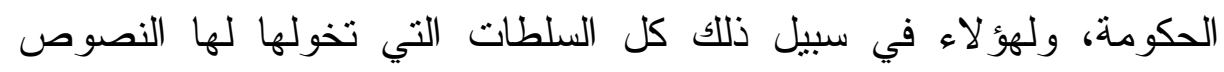

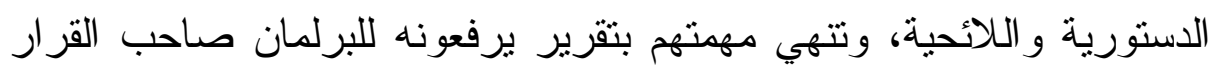
النهائي.

ولما كانت عملية التحقيق البرلماني تمارسه لجنة مؤلفة من عدد معين

من أعضاء البرلمان لتقصي الحقائق عن وضع علئ معين في أجهزة السلطة

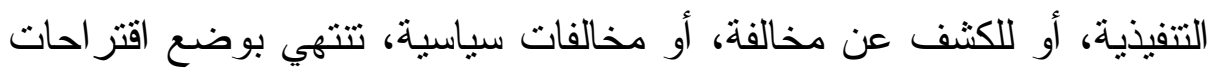
معينة (كتحريك المسئولية السياسية، أو إصلاح ضرر معين أو تلافي أخطاء

معينة).

وتباشر لجان البرلمان بمباشرة مهامها في دراسة وبحث الموضو عات

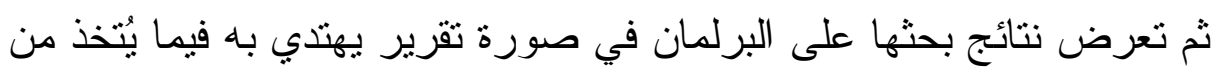

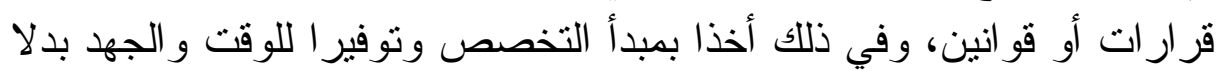

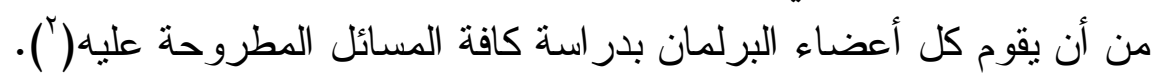

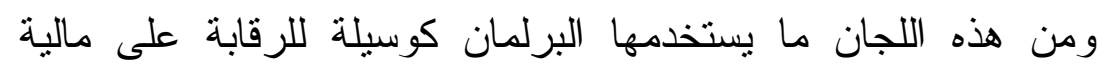

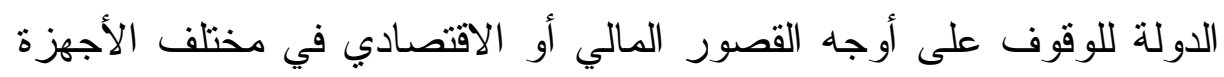
الحكومية لكي يتوصل المجلس بنفسه إلى ما يريد معرفتهمن الحقائق ، فإذا التها

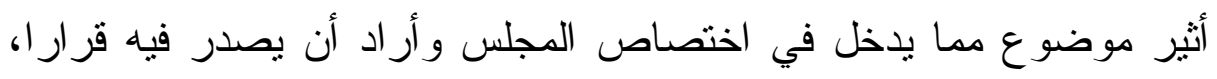

() د. دحمد باهي أبو يونس، الرقابة البرلمانية على أعمال الحكومــة، الإســكندرية، دار

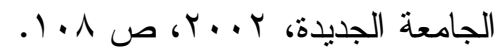

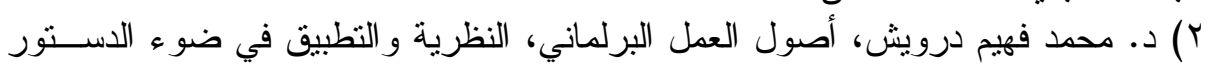

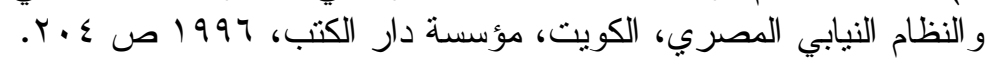


فأمامه أحد الطريقين(')، إما أن يقتتع بالبيانات التي تقدمها له الحكومة

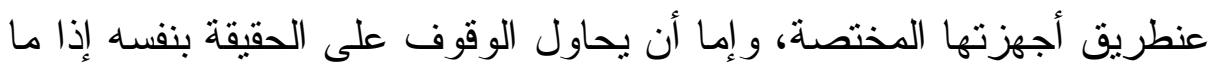

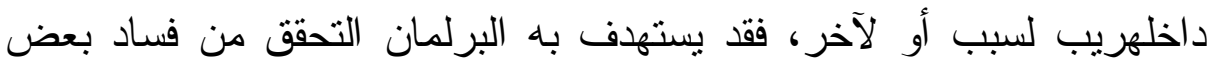

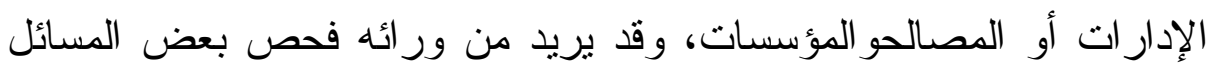
المنسوبة إلى أحد الوزر اء تمهيداًاتهامه.

ويتم تشكيل لجان البرلمان - ومن بينها لجان التحقيق - من أعضاء البرلمان، إذ يتم التهاء التهاء انتخاب أعضاء اللجان بالأغلبية النسبية، وهذا بخلاف لبناف نظام التمثيل النسبي

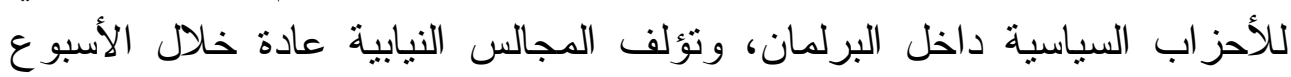
الأول من اجتماعه السنوي اللجان اللازمة لأعماله ويجوز لهذه اللجان أن تبانشر

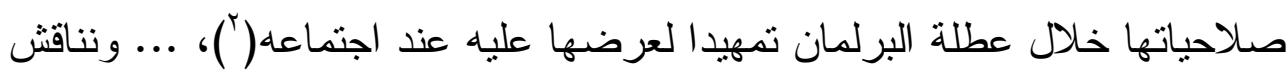
ذلك في البنود التالية: - مانية

أولا: عناصر المجال المالي الخاضع لرقابة لبة لجان التحقيق

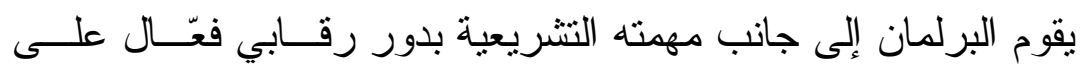

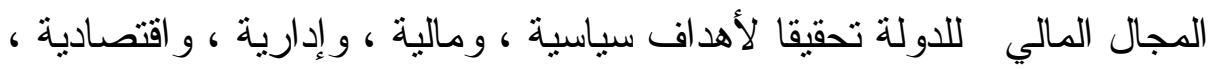

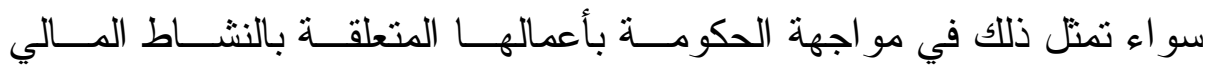

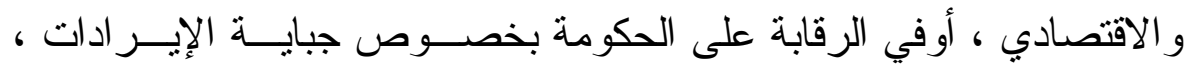

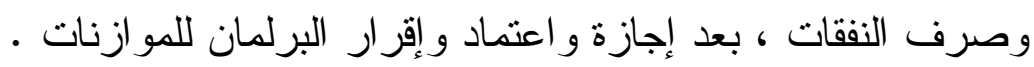

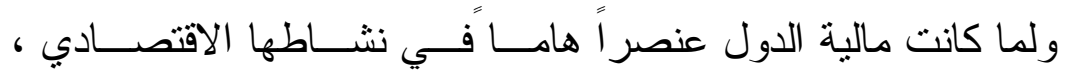

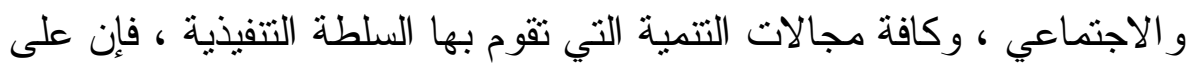
ممتلي الثعب بسط رقابتهم عليها بالوسائل الدستورية ، و القانونية للحفاظ على التى

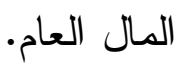

وفي سبيل ذلك يتعلق المجال المالي الخاضع لرقابة البرلمان وللجانـــه

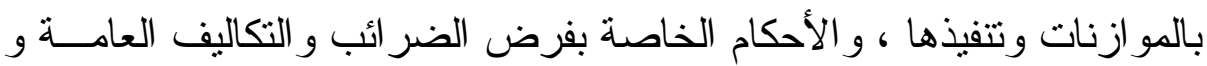

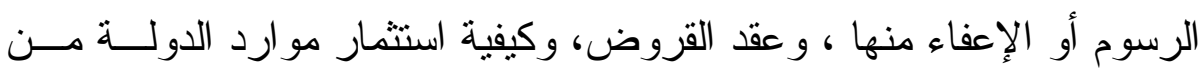

(1)د.عزيزة الثريف الاختصاص السياسي للبرلمان، مطبوعات مجلـس الأمــة الكـــيتي، r...V

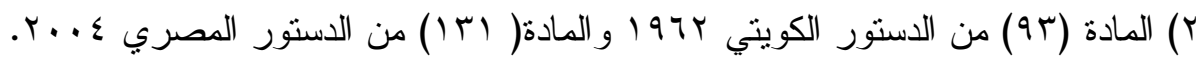


الثرو ات الطبيعية ، ومن حال امتياز ات أو الاحتكار ات، وشئون النقد و العملــة

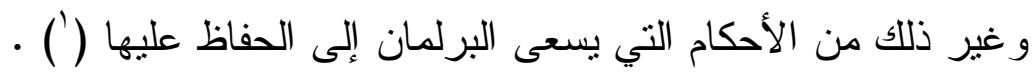

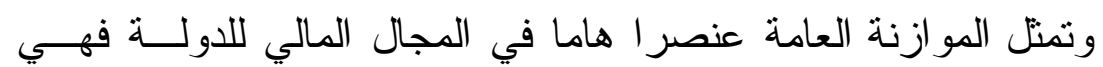

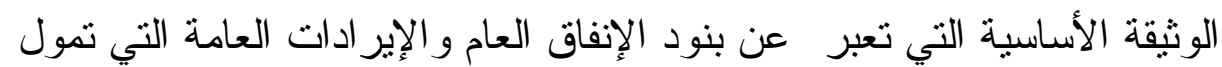

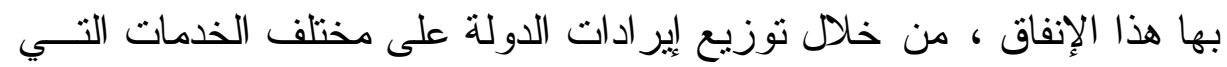
تقدمها لمو اطنيها.

ويتفق فقه المالية العامة على أن الموازنة اصطلاحا هي عبــارة عــن

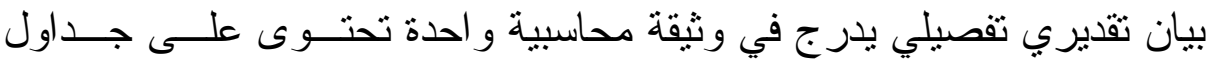

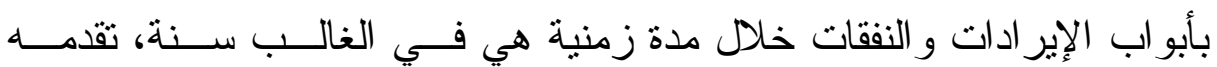

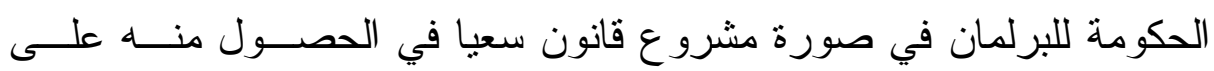

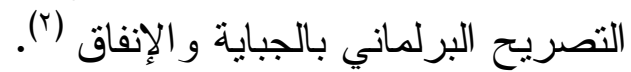

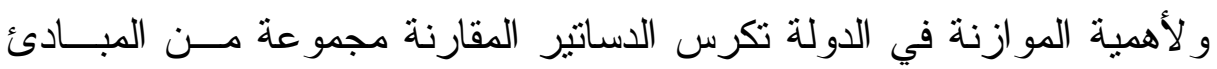

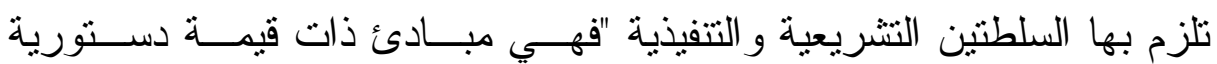

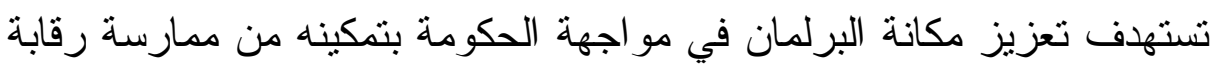

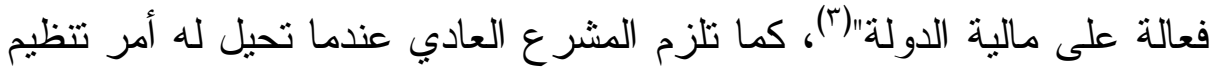
الموازنة بحيث لايخرج هذا التنظيم عن إطار التوازن و الثفافية و المصــــاقية

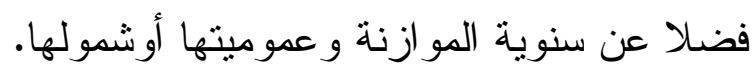
ثانيا: تشكيل لجان التحقيق البرلمانية في المجال المالي

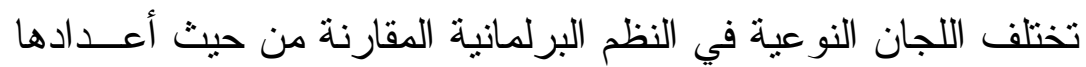

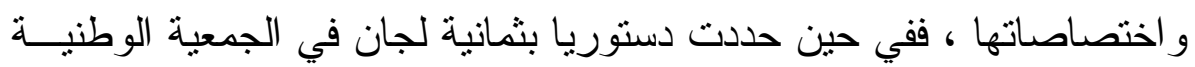

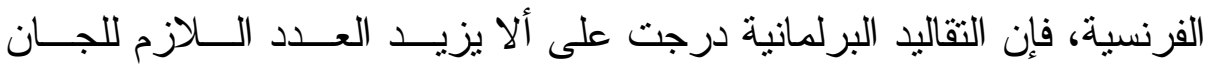

(')د.. عادل الطبطبائي، مرجع سابق، ص اسبهد. زين العابدين ناصر , مرجع سابق، ص

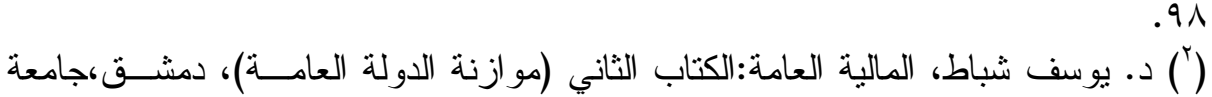

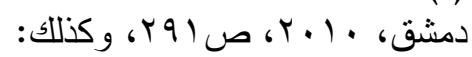
-REISMAN, CLAUDE and FAURE, PATRICK, Les acteurs de l'État déconcentré et la préparation de la LOLF à la veille de son entrée en vigueur In : La Revue du Trésor, n 11, , novembre, 2014 p. 582.

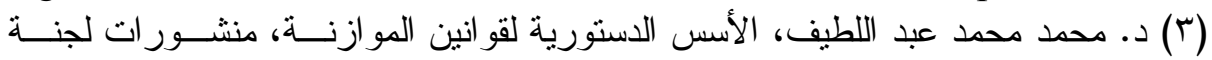

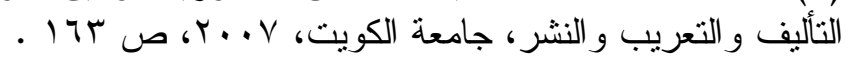


النوعية في مجلس الأمة الكويتي عن عشرة لجان دائمة، أما اللائحة الداخليــة

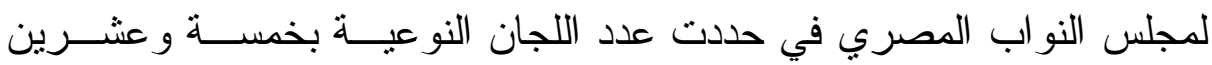
لجنة(') (ل)

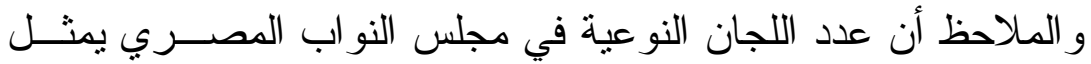

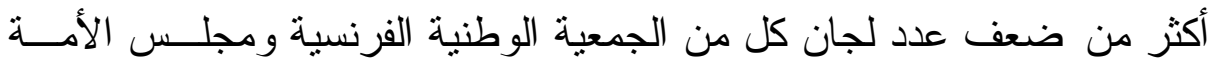

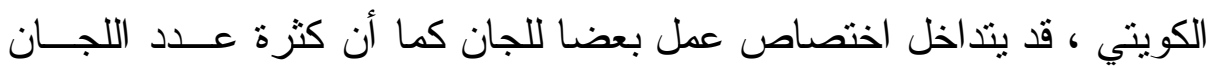

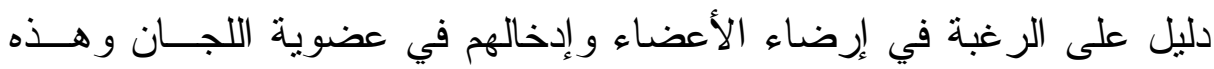

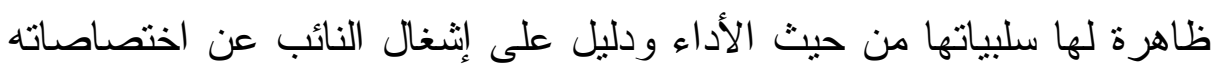
الرقابية.

وتختلف الأنظمة البرلمانية المقارنة في السند القانوني للعـدد الــلازم

لتلك اللجان النوعية الدائمة خلال الفصل التشريعي للبرلمان ، فقد يستتد تشكيل

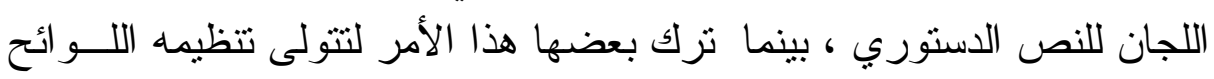
الداخلية للبرلمانات.

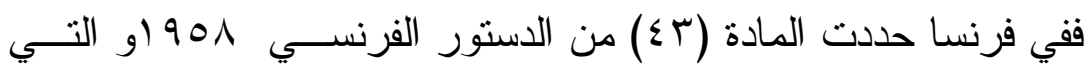

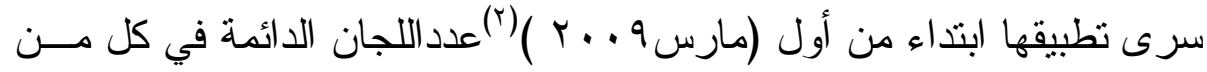

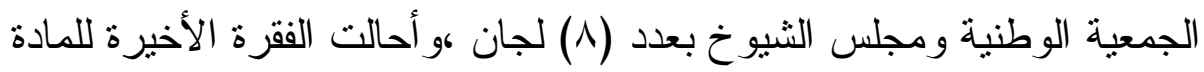

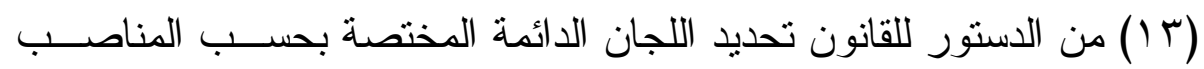

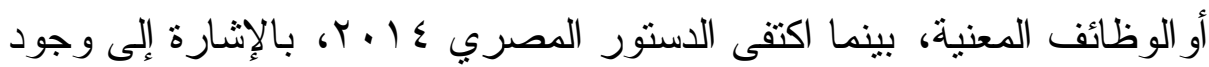

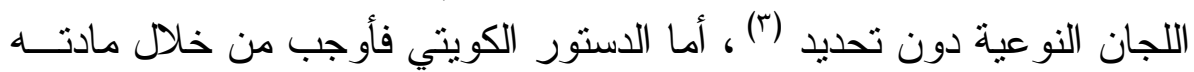

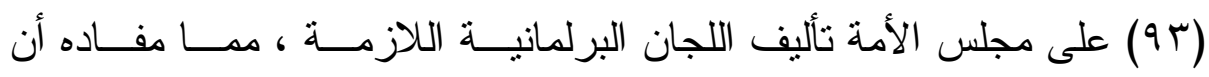

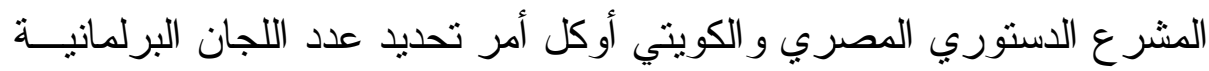

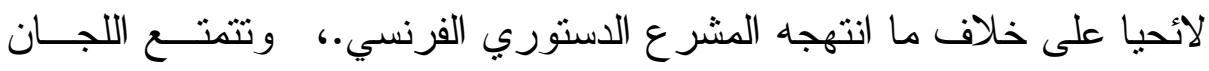

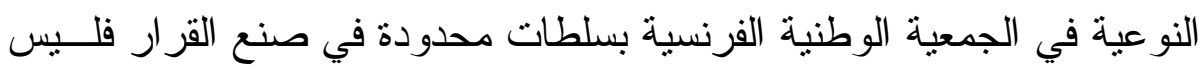

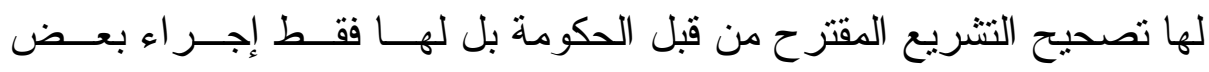

$$
\text { ( ) المادة (YrV) من اللائحة الداخلية لمجلس النواب المصري. }
$$

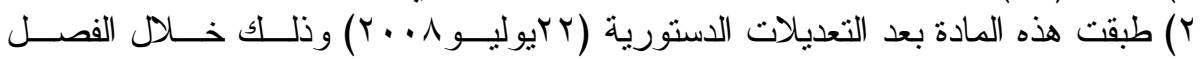

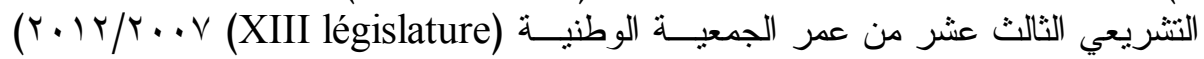

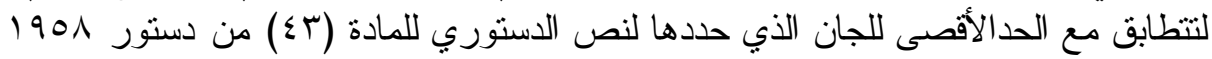

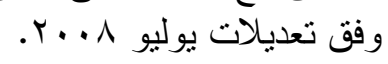

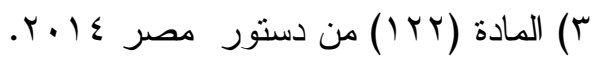




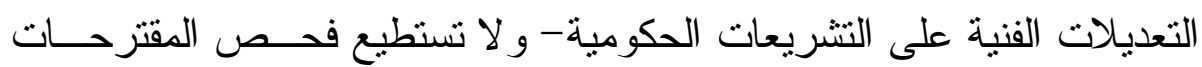
الحكومية بالعناية الكافية(')

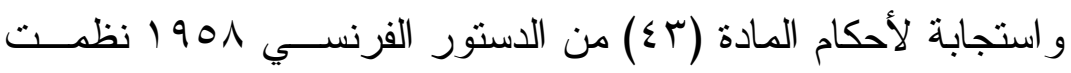

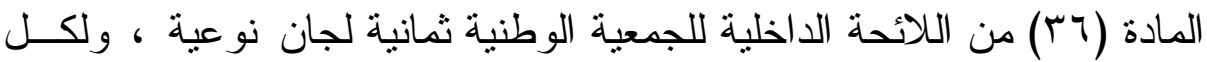

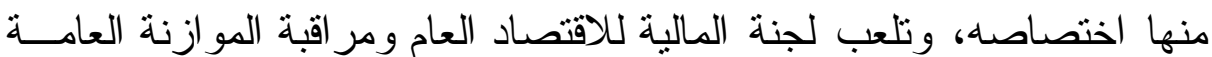
دور هام في تحقيق التوازن المالي قبل اعتماد مشروع قانون الموازنة.

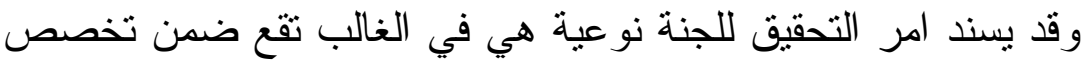

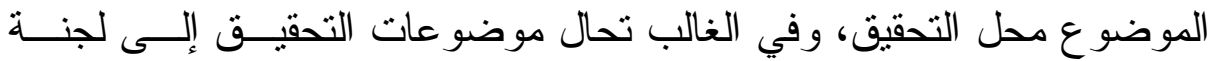

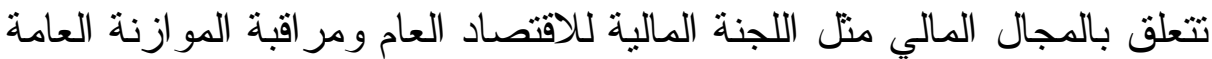
Commission des finances, de l'économie générale et du contrôle budgétaire

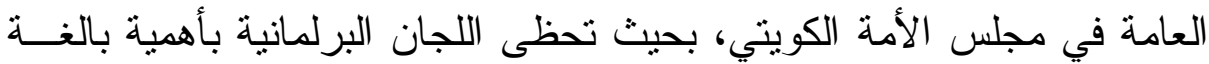

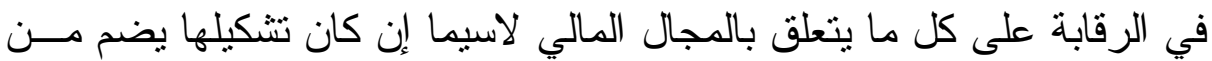

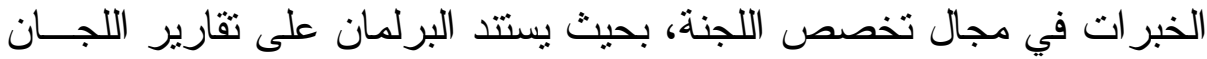
عند أداء الرقابة.

وتلعب اللجان البرلمانية بشكل عام واللجان ذات الاهتمام بالجانب الانب المالي على وجه الخصوص دور ا هاما في الرقابة البرلمانية على الأمو ال العامة، فهي التي تمد البرلمان بالتقارير التي يستطيع من خلالها بسط رقابله

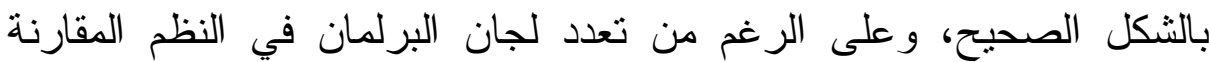

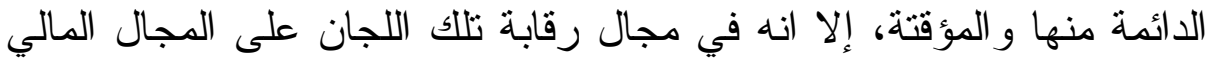
تبرز منها اللجان ذات الطابع الاقتصادي و المالي وحماية المال العام والتي يصب اهتمامها بطبيعة عملها سواء بالنسبة للجانب التشريعي أو الجانب ولبه الرقابي، ويبرز من اللجان البرلمانية في مجلس الأمة التي تعاون البرلمان لهان

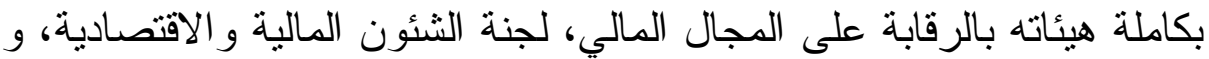
لجنة الميز انيات و الحساب الختامي، لجنة حماية الأمو ال العامة.

1)KOTT, SEBASTIEN, histoire économique et financiered de la France: le contrôle des dépensesengagées. elevolution d'une fonction, paris: comité pour l'histoire économique etfinancière de la France, 2004, p177. 


\section{ثالثا: تكليف لجنة نوعية أو تثكيل لجنة موقتة للتحقيق في المجال المالي}

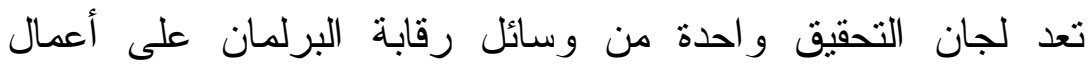

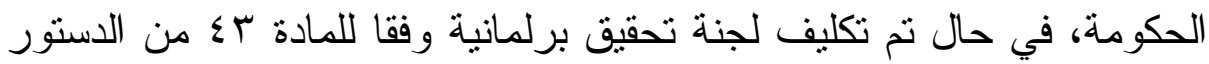

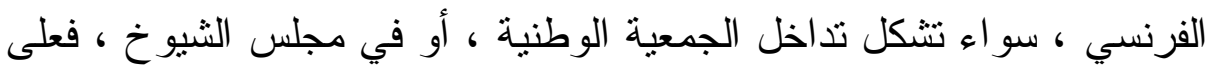
هذه اللجنة المكلفة أن تجمع المعلومات التي مبناها وقائع محددة، وتقدم نتائج التحقيق الى المجلس الذي كلفها. (') ويخير المشرع في النظم المقارنة البرلمان وهو بصدد بسط رقابته في المجال

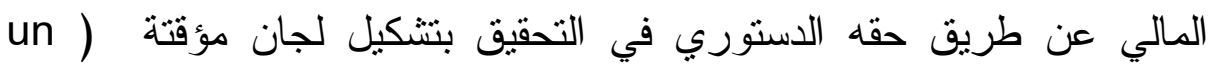
(caractèretemporaire الدائمة بأمر التحقيق في المسالة المتعلقة بالمجال المالي.

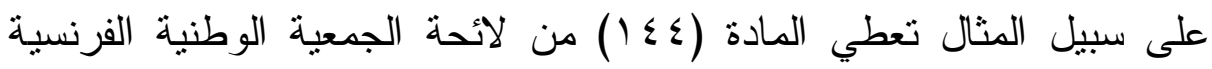

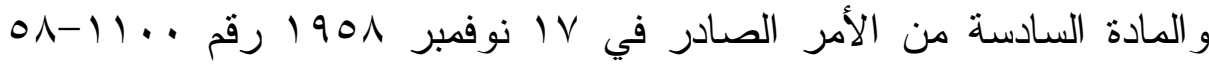
الخاص بتتظيم عمل المجالس النيابية، مدة أقضاها ستة أثنهر لانتهاء عمل لجنة التحقيق فإذا لم تقدم تقرير ها بعد هذه المدة، يجب على لثلى رئيس اللجنة تقديم

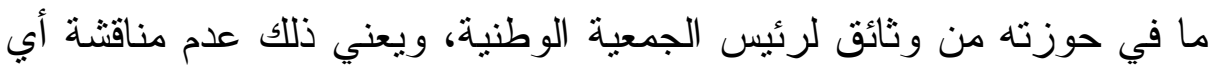
منشور ات تتعلق بعمل اللجنة.

ويتم تشكيل لجان التحقيق البرلمانية في الجمعية الوطنية الفرنسية وفق الجق

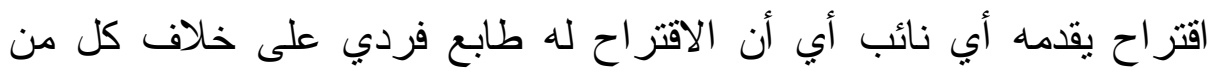

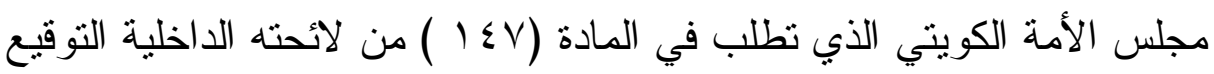

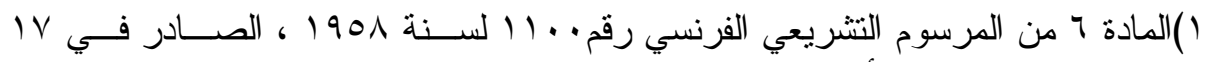
نوفمبر، 1901 المتعلق بأداء المجالس النيابية. -(Ordonnance $\quad \mathrm{n}^{\circ} \quad 58-1100 \quad \mathrm{du} \quad 17$ novembre 1958 relative au fonctionnement des assemblées parlementaires)

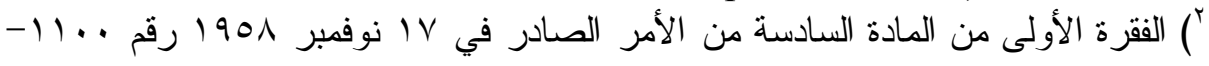
هor الخاص بتتظيم عمل المجالس النيابية - Les commissions d'enquête ont un caractère temporaire. Leur mission prend fin par le dépôt de leur rapport et, au plus tard, à l'expiration d'un délai de six mois à compter de la date de l'adoption de la résolution qui les a créées. Elles ne peuvent être reconstituées avec le même objet avant l'expiration d'un délai de douze mois à compter de la fin de leur mission 
من خمسة أعضاء على الأقل لاقتر اح تشكيل لجنة تحقيق، أما ومجلس النواب

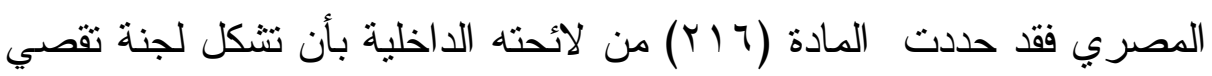
الحقائق بقرار من المجلس بناء على طلب اللجنة العامة أو إحدى اللجان

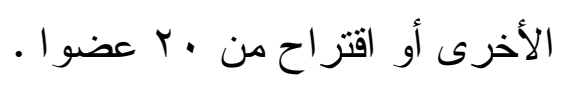

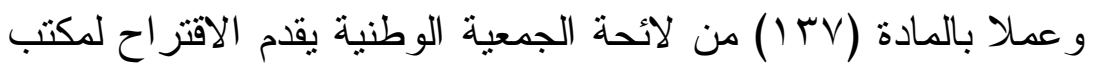

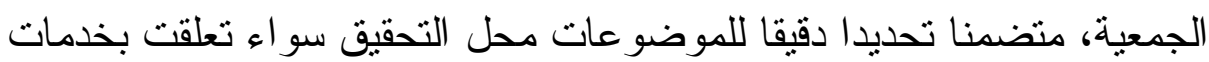
أو مشرو عات عامة وجب على اللجنة التحقيق فيها (').

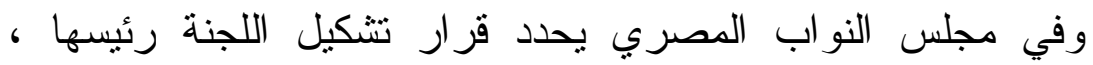
وتختار أمانة خاصة باللجنة من بين أعضائها أو من بين العاملين بالأمانة العامة للمجلس بناء على ما يقترحه رئيسا للجنة (').

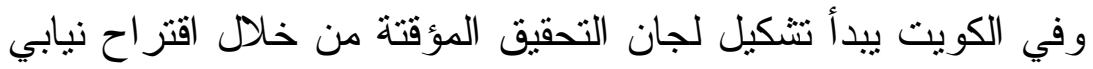
بطلب تتكيل اللجنة موضحا فيها لموضوع محل التحقيق و الغرض منه ، فإذا

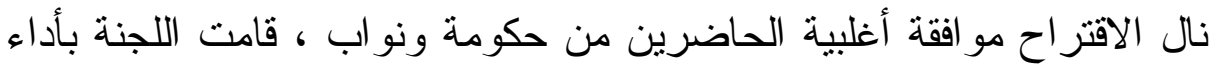

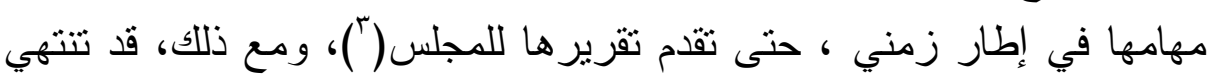

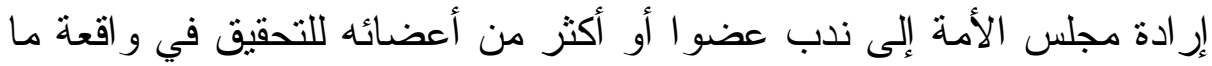

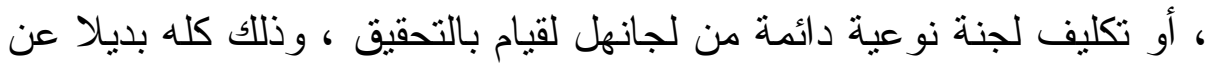
تشكيل لجنة مؤقتة للتحقيق ، و لا يجوز أن يقل عدد أعضاء اللجنة ألجنة المشكلة لتقصي الحقائق في مجلس النواب المصري عن سبعة ، ولتهي ، و لا يزيد على خمسة

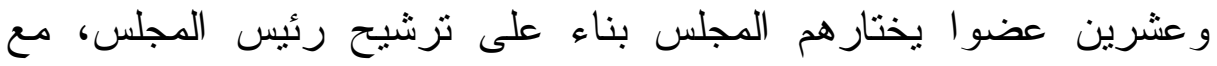

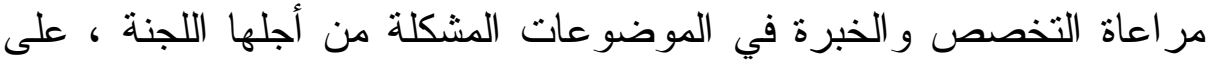

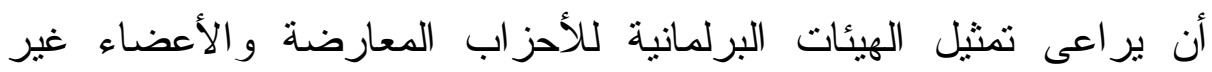

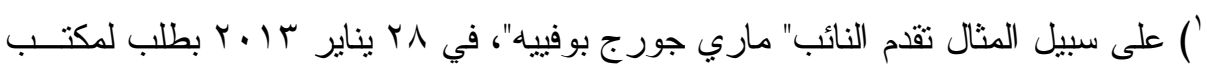

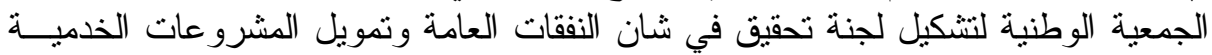
المخصصة لسكان " Seine-Saint-Denis,

- ASSEMBLÉE NATIONALE, QUATORZIÈME LÉGISLATURE. Enregistré à la Présidence de l'Assemblée nationale le 28 janvier 2013, $\mathrm{N}^{\circ}$ 657. http://www.assemblee-nationale.fr.

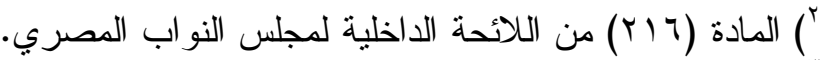

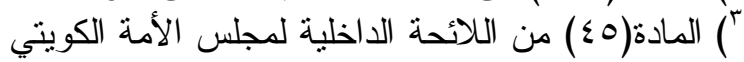


المنتمين للأحز اب إذا كان عددهم في المجلس لا يقل عن عشرة أعضاء(')،

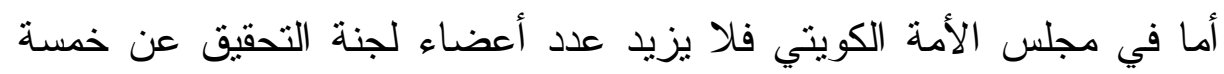
أعضاء.

رابعا : عمل واختصاصات لجان التحقيق البرلمانية في المجال المالي:

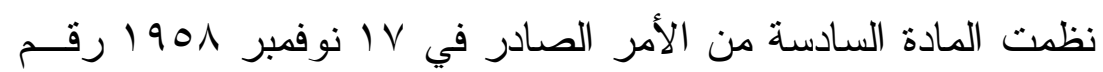

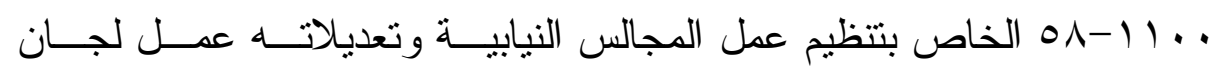

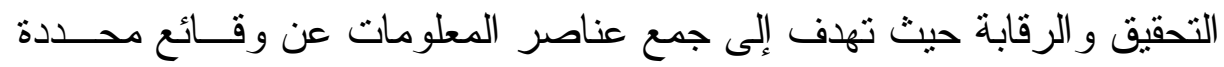

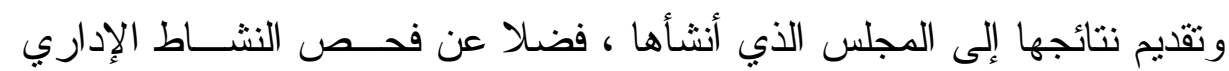

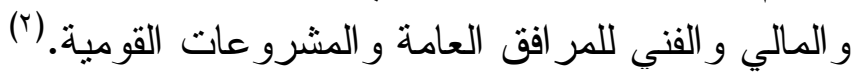

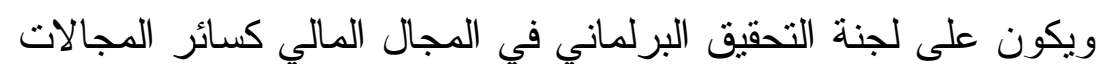

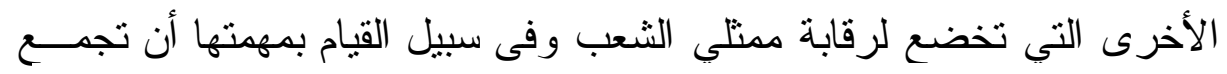

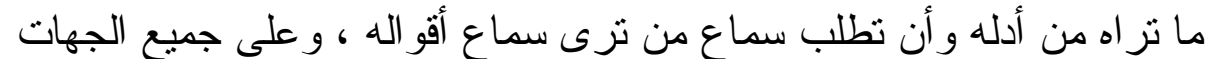
أن تستجيب إلى طلبها و أن تضع تحت تصرفها ما تطلبه من وثائقأ ومستتدات

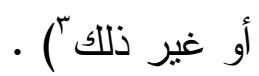

\section{المبحث الثاني}

التحقيق البرلماني في المجال المالي في واقعه العملي

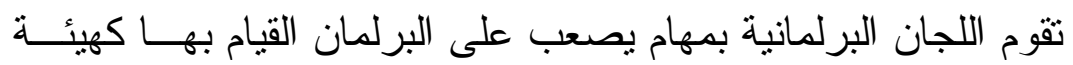

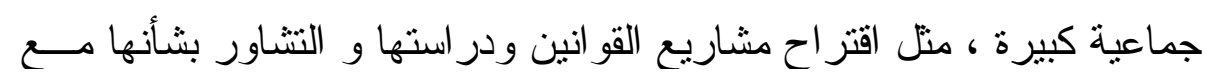

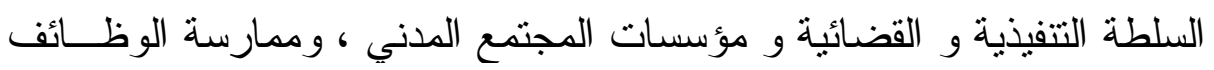

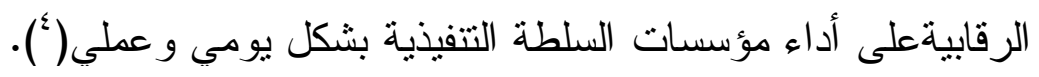

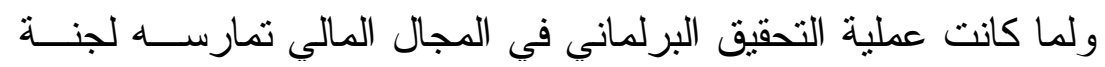

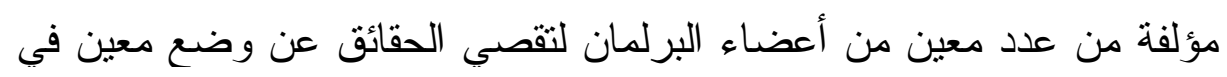

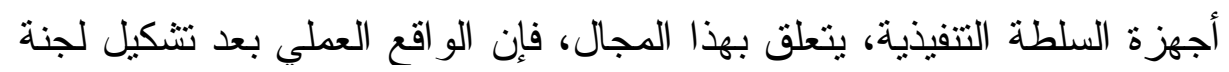

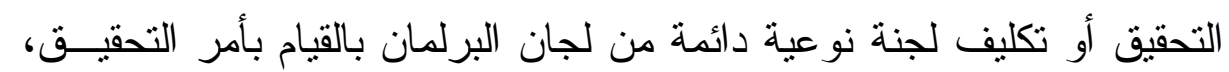

${ }^{2}$ ) l'article 1er de la loi no 2011-140 du 3 février 2011

$$
\text { ') المادة(r/Y/r) امن اللائحة الداخلية لمجلس النواب المصري }
$$

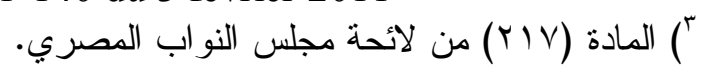

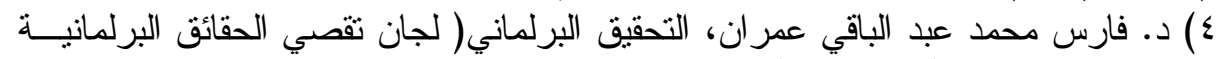

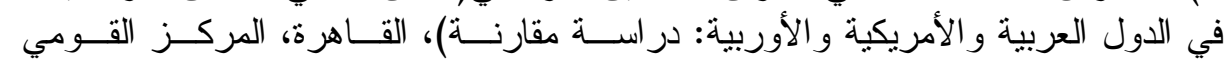

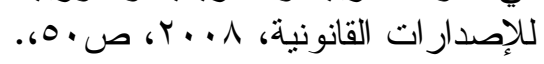


لابد أن يمر بإجر اءات و اقعية ليست نظرية تتطلب من أعضاء اللجنة البحــث

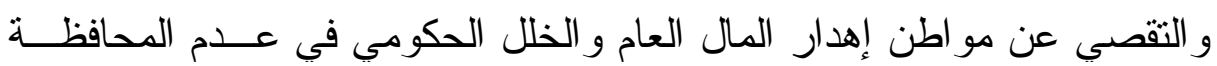

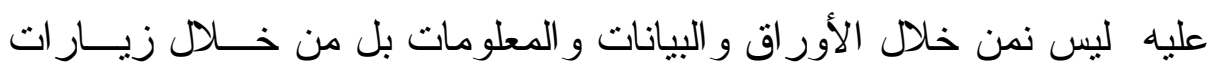

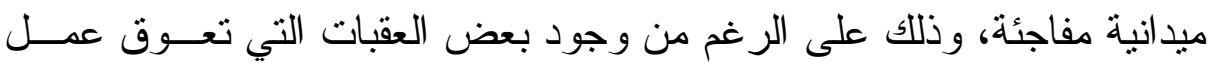

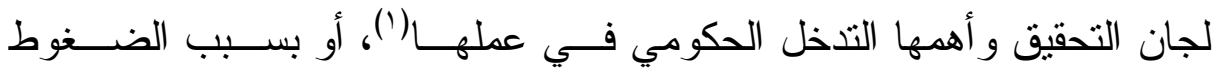

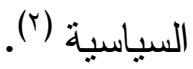

ويقتضي الحديث عن الواقع العملي للجان التحقــق البرلمــاني فــي

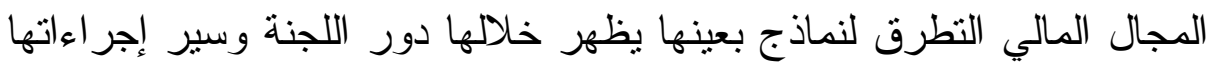
و الآثار المتزنبة على التحقيق في المجال المالي على النحو التالي:

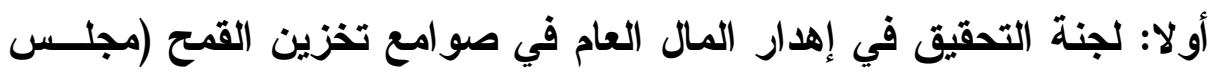
النواب (المصري) تشكلت هذه اللجنة بناء على طلب عدد من النواب لاحظو ا وجود عدة معوقات تحول دون وصول الدعم النقدي لمحصول القمح لمستحقيه ، أبرزها: عدم وجود تصوير جوى حديث ودقيق لجميعم ساحات الأر اضي الزر اعية في

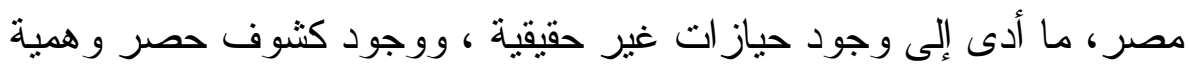

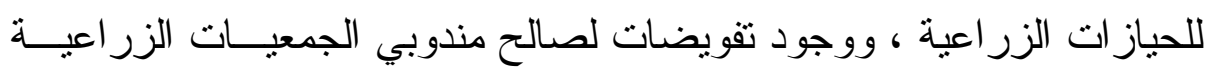
لاستلام مقابل توريد القمح ، وبناء على هذه التقويضات يقوم مندوب و والجمعية

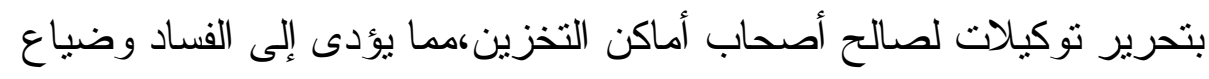
حقوق المزار عين.

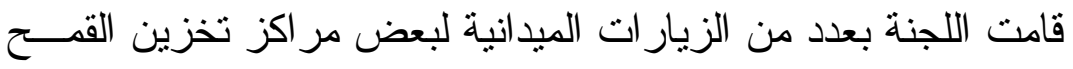

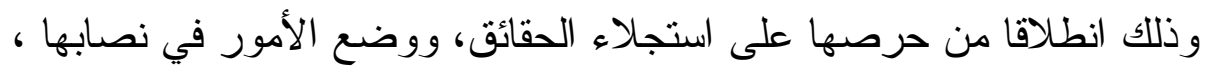

( ) مناور بيان مناور الراجي،التحقيق البرلماني وتطبيقاته في دولة الكويت ، مؤسسة دار

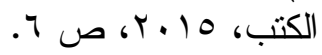

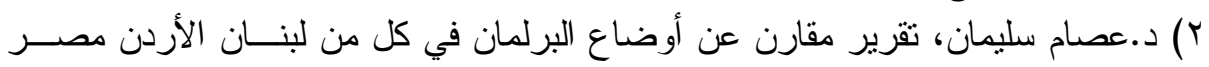

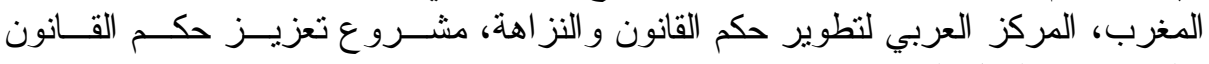

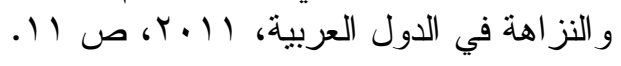


و استعانت في تلك الزيار ات بإحدى الثركات العالمية المعتمدة المتخصصة في

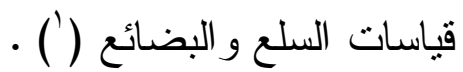

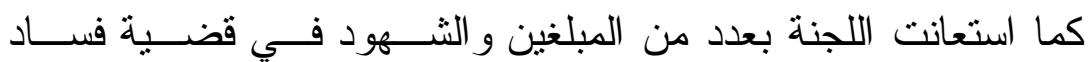

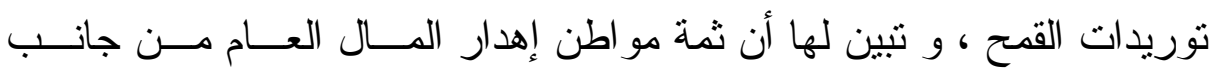

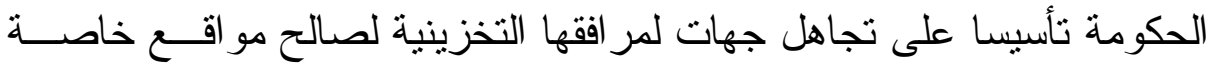

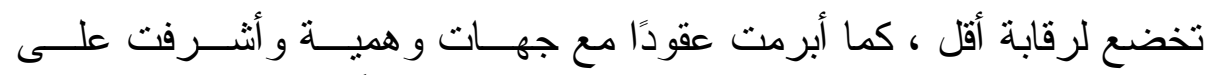
إصلاحات معيبة تسببت في زيادة الإنفاق على الدعم بدلًا من تخفيضه كما هو هو هون معلن.

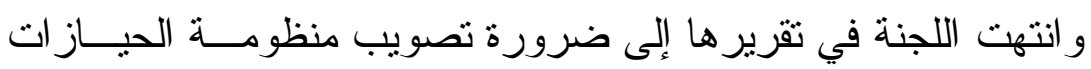

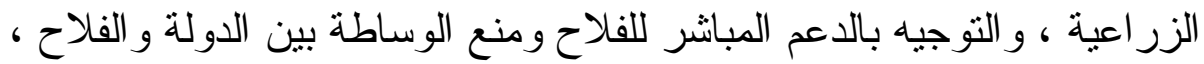

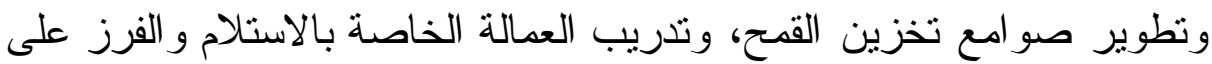

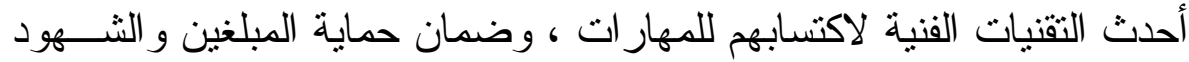

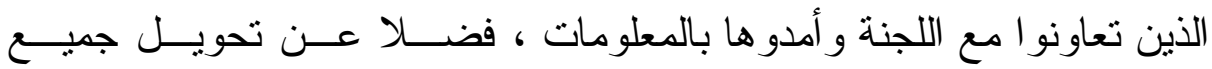

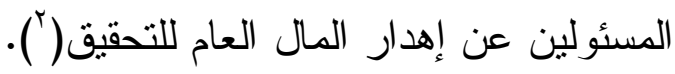

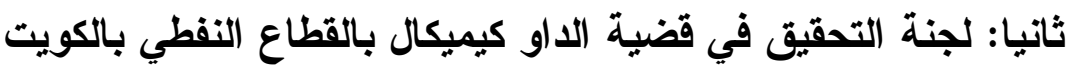
قد لا يكون تقرير لجنة تقصي الحقائق ذات قيمة في الرقابة البرلمانية

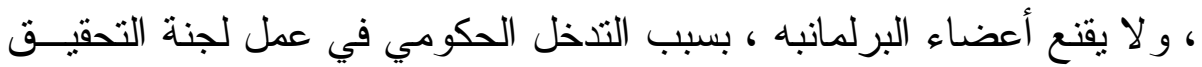

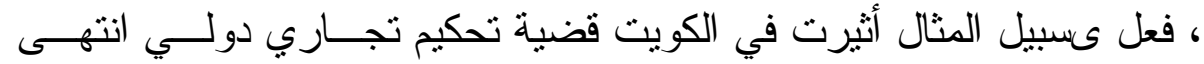

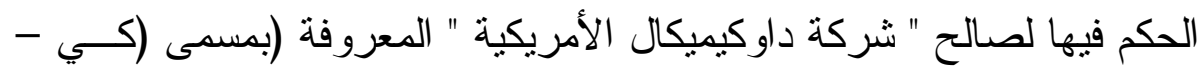

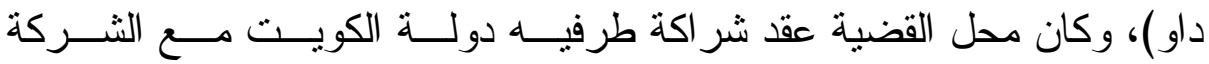

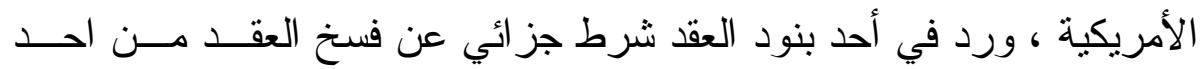

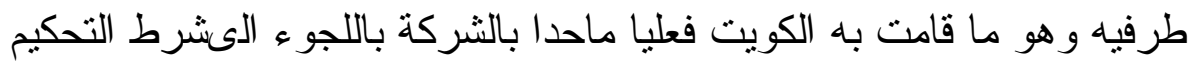
و المطالبة بالثرط الجز مائي.

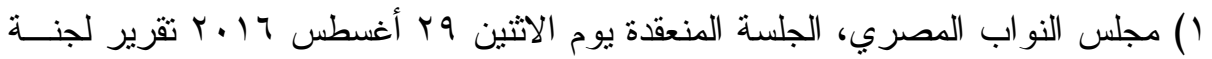

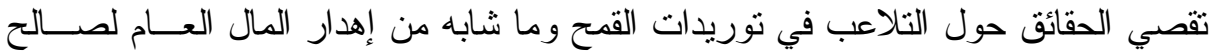

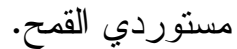

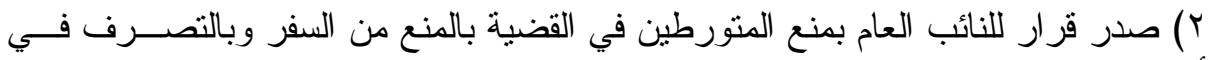

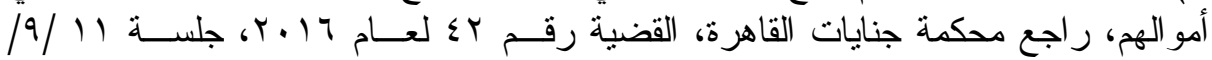




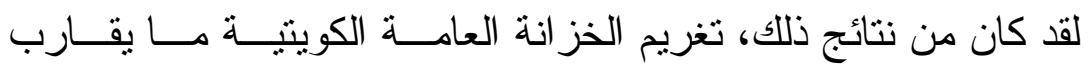

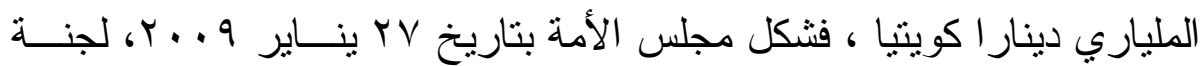

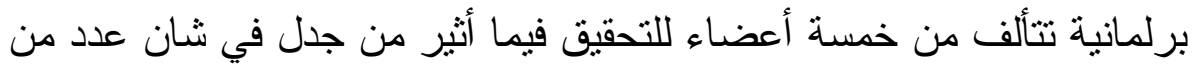

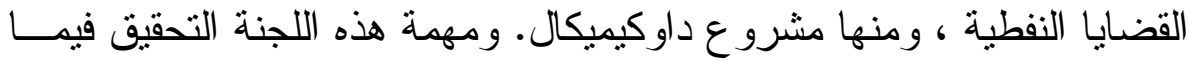

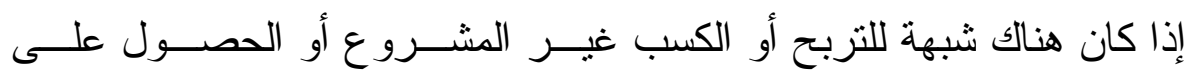
عمو لات من أبي نوع كان ، ولمصلحة أي جهة أو شخص شار شارك فئرة فيها بصورة

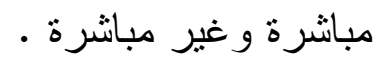

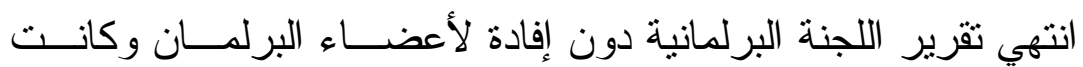

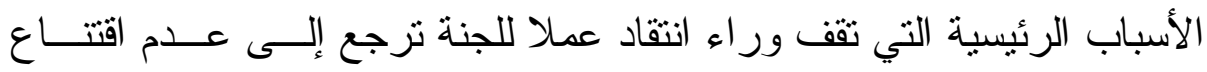

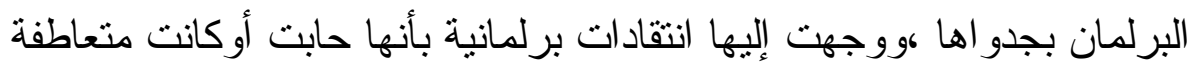

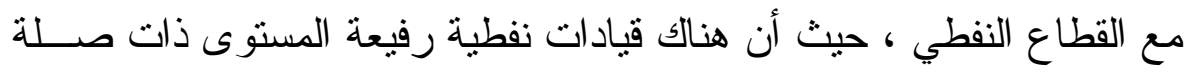

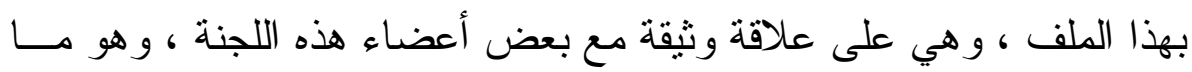
انعكس بطبيعة الحال على عمل اللجنة(').

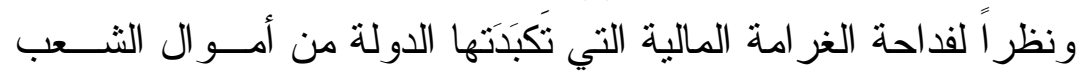

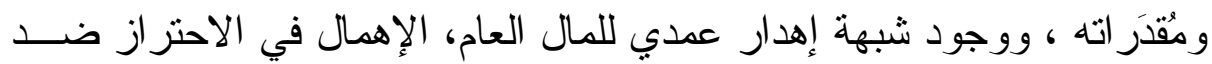

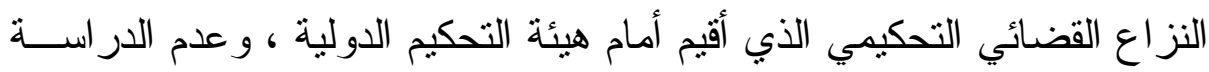

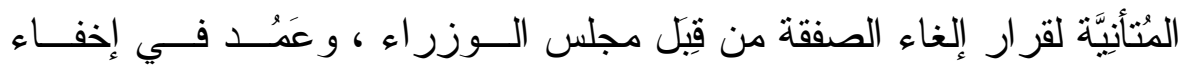

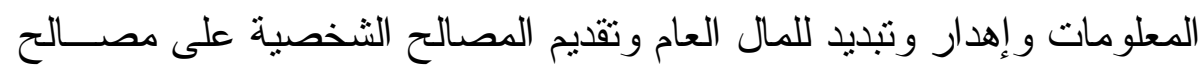

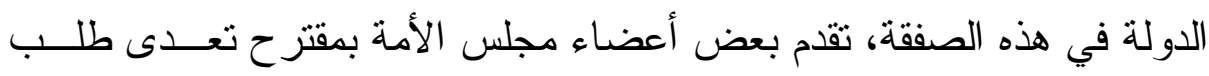
تشكيل لجنة تحقيق، وذللك من ز اويتين( (ك) :

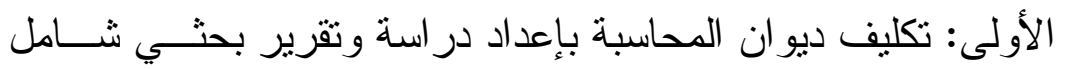

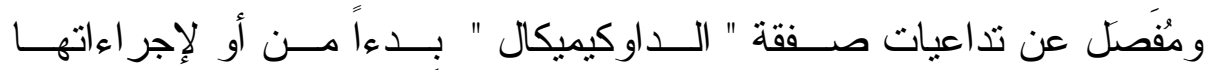

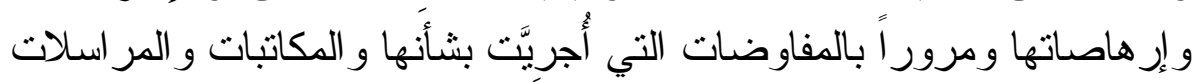

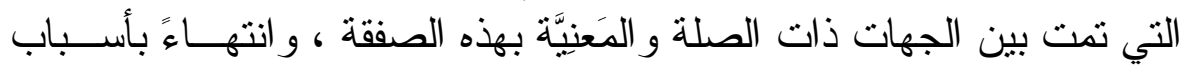

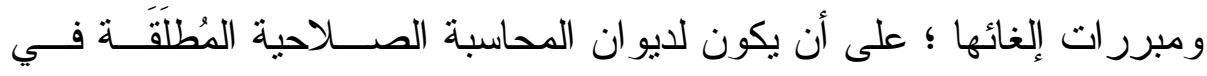

( ) الكويت، مجلس الأمة، جلسة مناقشة تقرير اللجنة البرلمانية المشكلة للتحقيق في قضـــية

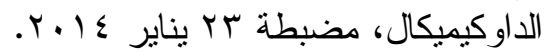

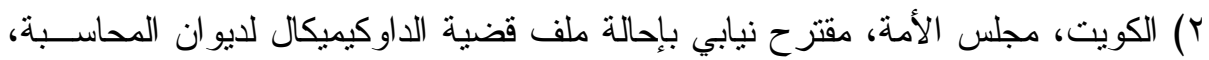

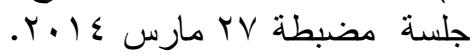




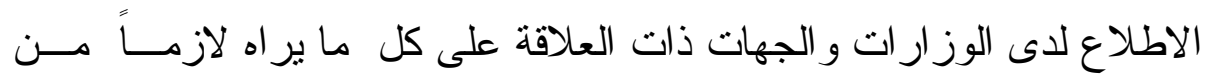

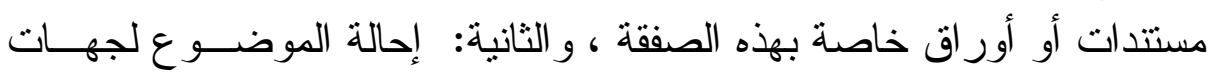

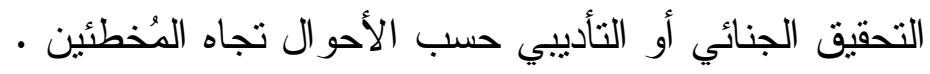

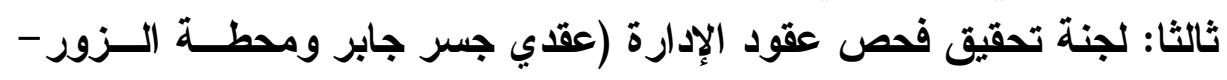
(الكويث): تشكلت لجنة مؤقتة بمجلس الأمة الكويتي لفحص إهدار المال العام

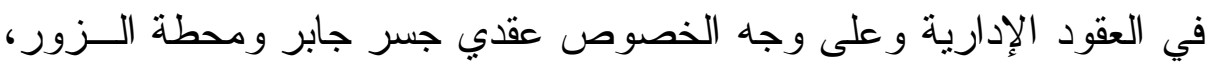

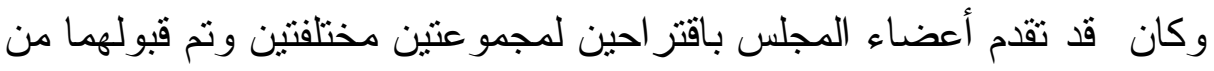

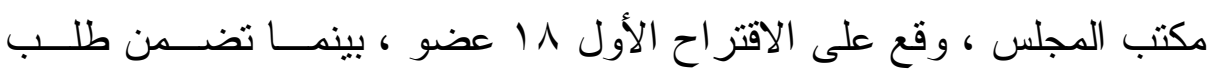

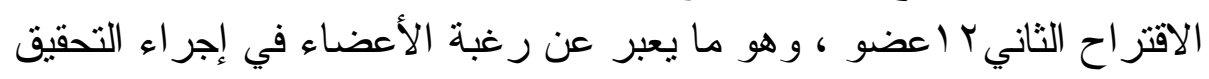
، ومع ذللك جرى التصويت بضم الاقتر احين و اختبار لجنة تحقيق و احدة.

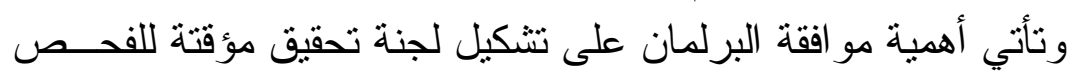

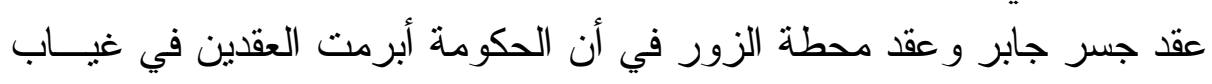

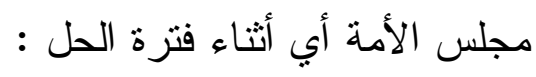

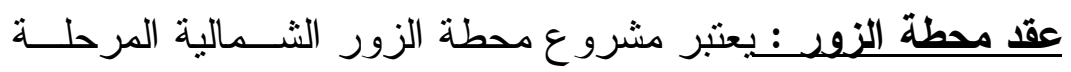

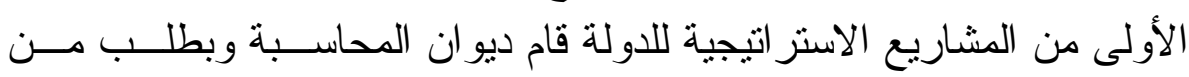

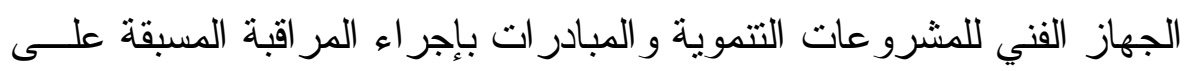

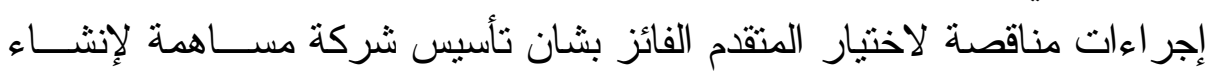

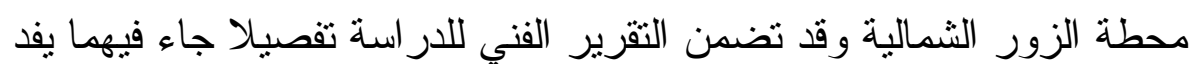

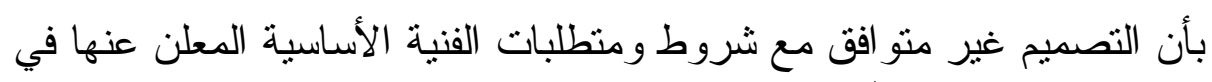
طلب تقديم العروض ').

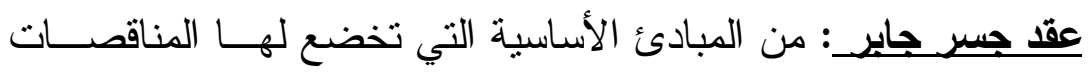

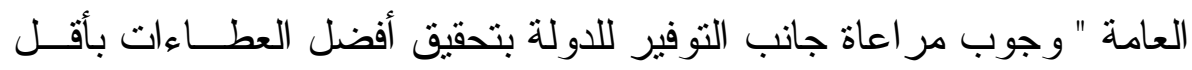

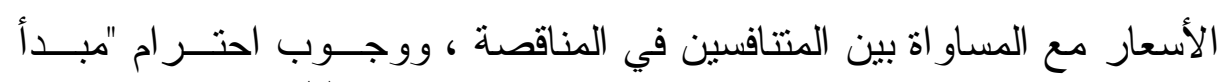

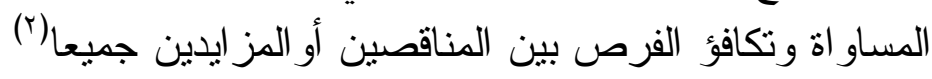

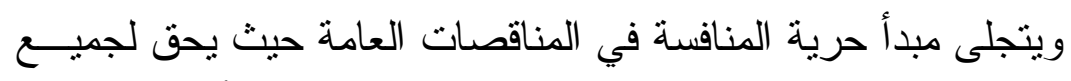

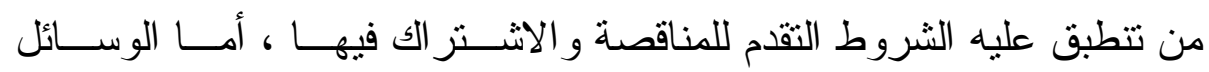

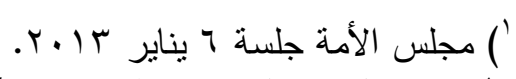

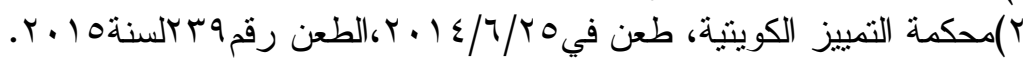


الأخرى للعقود فمن شأنها التضبيق من هذا المبدأ إلى أن ينعدم كما هو الحـــال

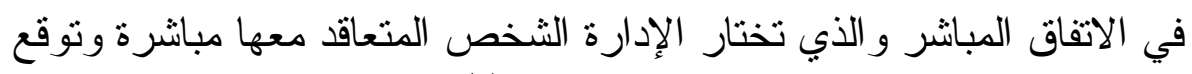

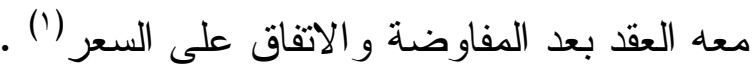

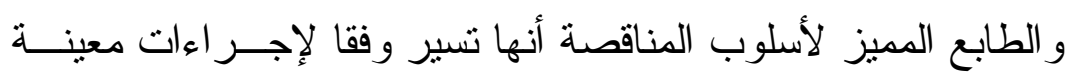

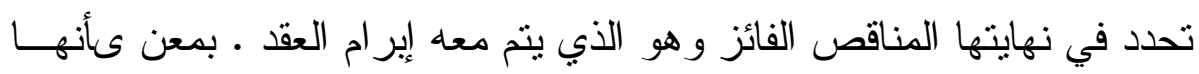
تسلب الإدارة كل حرية في تحديد من تتعاقد معه وتكل ذلك إلى الطريق الــــي تشير فيه المناقصة (r).

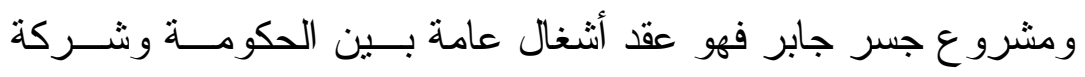

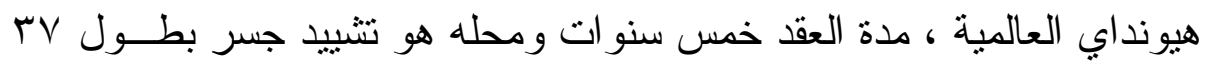

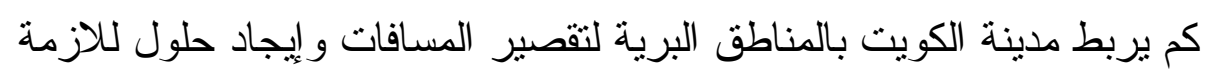

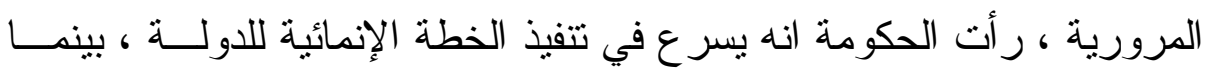

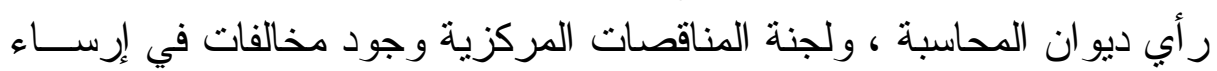

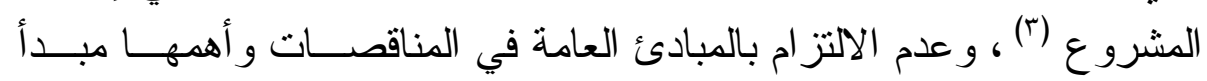
التزسية على السعر الأقل.

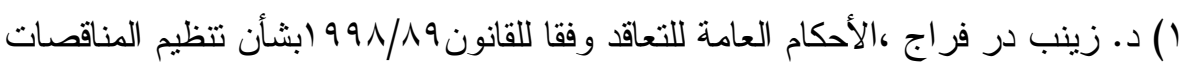

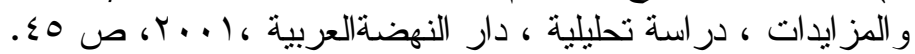

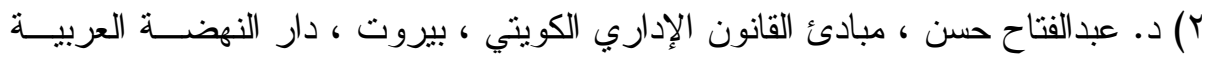

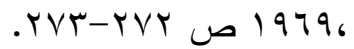

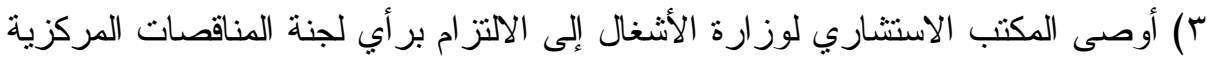

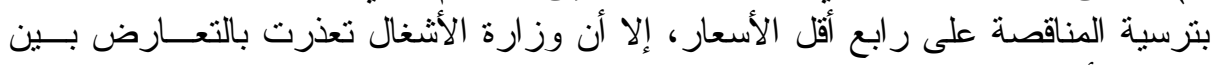

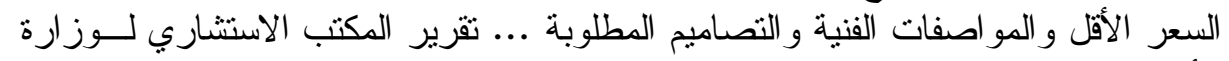

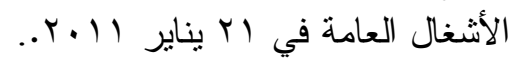




\section{خلاصة البحث}

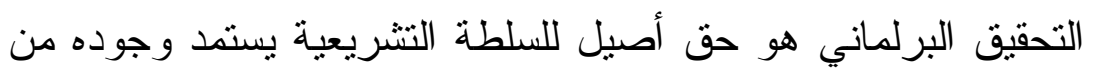

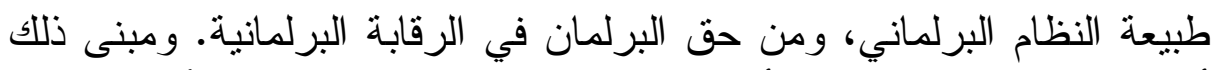
أن لجان التحقيق البرلمانية أو لجان تقصي الحقائق هي بحسب التئن الأصل وسائل رقابية دستورية.

و على الرغم من أن أعضاء اللجان هم بحسب الأصل أعضاء البرلمان

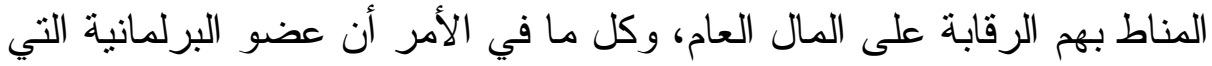

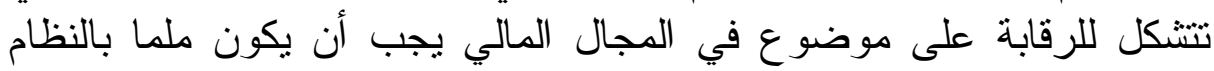

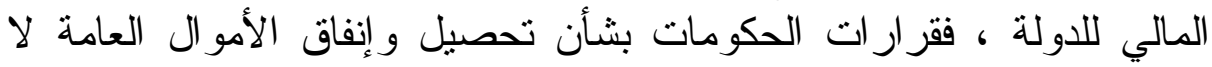

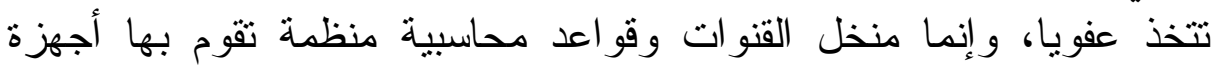
ومؤسسات الدولة التي تمارس النشاط المالي لها.

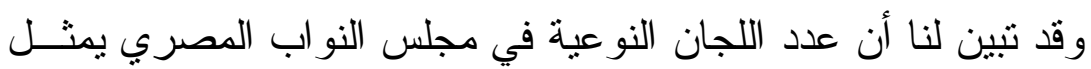

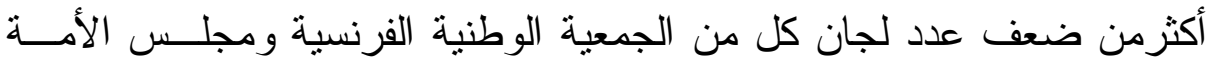

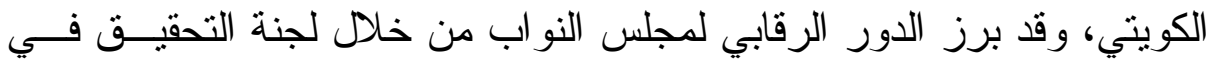

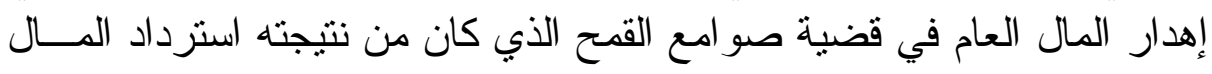
العام ومحاسبة المقصرين جنائيا.

كما ظهر من الدراسة أن في مكنة لجان التحقيق استدعاء الثهود مما

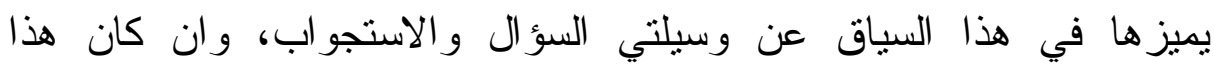

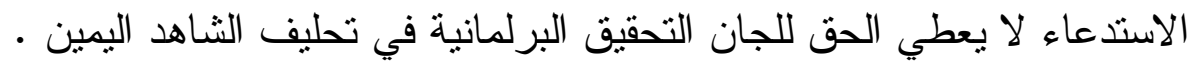

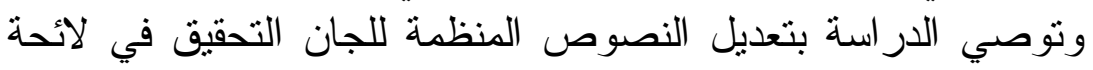

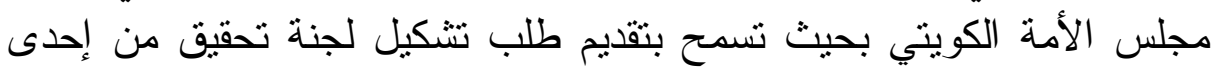

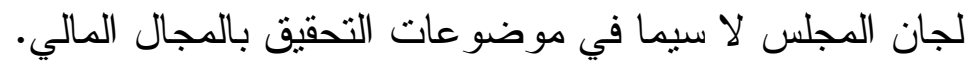

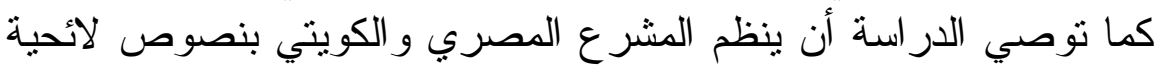

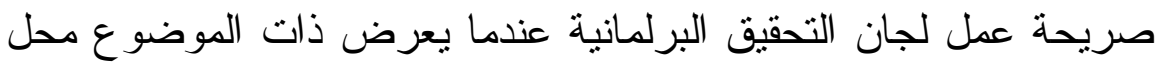

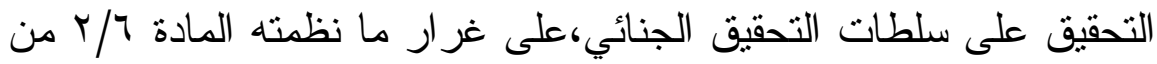

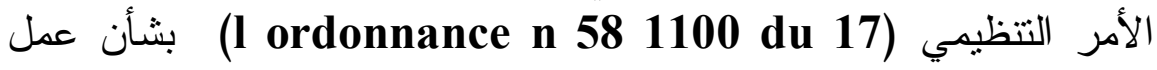

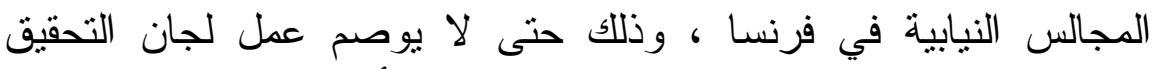

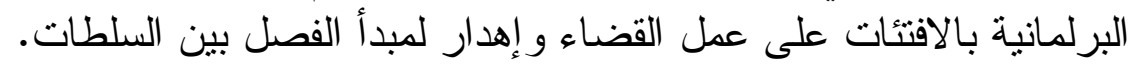

